\title{
Commentary: Do not kill (especially for nothing)
}

\author{
Irbaz Hameed, MD, and Mario Gaudino, MD
}

\author{
From the Department of Cardiothoracic Surgery, Weill Cornell Medicine, New York, NY \\ Disclosures: Authors have nothing to disclose with regard to commercial support. \\ Received for publication July 7, 2019; accepted for publication July 8, 2019; available ahead of print Aug 20, \\ 2019. \\ Address for reprints: Mario Gaudino, MD, Department of Cardiothoracic Surgery, Weill Cornell Medicine, 525 \\ East 68th St, New York, NY 10065 (E-mail: mfg9004@med.cornell.edu). \\ J Thorac Cardiovasc Surg 2019;158:1557-8 \\ $0022-5223 / \$ 36.00$ \\ Copyright (C 2019 by The American Association for Thoracic Surgery \\ https://doi.org/10.1016/j.jtcvs.2019.07.050
}

In this issue of The Journal of Thoracic and Cardiovascular Surgery, Santer and colleagues compare postcardiopulmonary bypass hemodynamic recovery of pig hearts using polarizing versus depolarizing cardioplegia. After an extensive experimental work, the authors conclude that their results suggest "the noninferiority as well as the potential benefits of a novel hypothermic blood-based polarized St Thomas' Hospital cardioplegic solution in a clinically relevant model of CPB [cardiopulmonary bypass] in pigs."

The key problem is the definition of "clinically relevant." It is unclear how a model on the basis of healthy nonprimate hearts undergoing a period of cardiopulmonary bypass and aortic cross-clamping without any surgical intervention (luckily a scenario relatively infrequent in human practice) might be "clinically relevant" for humans with heart disease submitted to surgical repair.

The results of Santer and colleagues ${ }^{1}$ are probably "clinically relevant" for surgeons interested in performing cardiac surgery on healthy pigs, but do they have any relevance for humans? Can we learn something applicable to our surgical practice from the complex experimental effort of the Vienna group? In alternative, does this work provide important hypothesis-generating data to be tested in a human trial? The answer to all the questions is a clear no.

The problem of extrapolating animal results to humans is not new. Alexander Pope's quotation "The proper study of mankind is man" is widely cited. ${ }^{2}$ There is solid evidence that most animal models fail to translate to human clinical research ${ }^{3}$ (clinical practice is far off). This is true even for surgical animal models. ${ }^{4}$ The key problem is obviously related to the important interspecies differences that make animal results poorly reproducible in humans. In addition, most animal studies are poorly designed and conducted and have major methodological flaws. Santer and associates ${ }^{1}$ in the first version on the report did not provide any attempt at sample size calculation and, upon reviewers request, provided an estimate on the basis of a

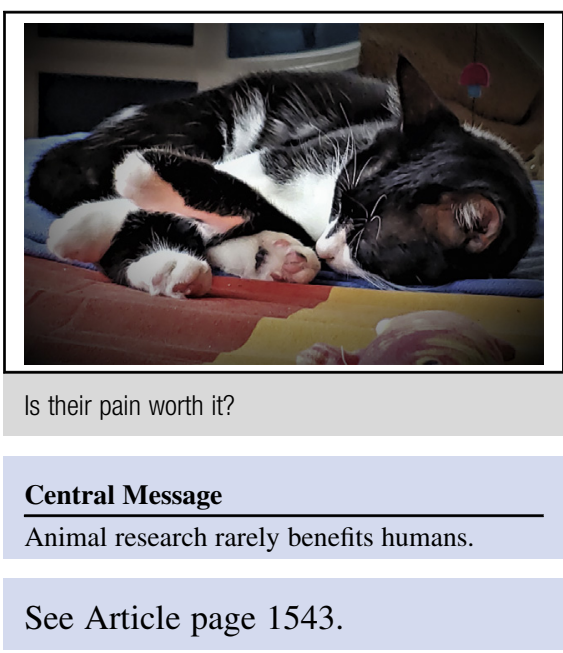

rat model (adding another interspecies difference to the equation) and on an unsubstantiated definition of superiority. In addition, while presenting a very long list of hemodynamic, biochemical, and histologic outcomes, they do not consider adjusting for multiple testing. It has been argued that animal models must be designed to mimic human disease and treatment as closely as possible. ${ }^{5}$ This was not the case for Santer and colleagues, ${ }^{1}$ who studied healthy pigs undergoing isolated cardiopulmonary bypass and aortic clamping. ${ }^{1}$

It is known that human clinical trials have been performed despite evidence of harm of the tested intervention in animal models. ${ }^{6}$ This implies that animal data were regarded as irrelevant to inform human clinical research, putting into question why the experiments were performed in the first place. ${ }^{6}$ It is even contended that animal models might be harmful to humans through misleading safety and efficacy results, misdirecting resources away from more effective methods, and potential rejection of useful medical treatments. ${ }^{7}$ With the current immense potential of simulation technology, the use of animal models raise major methodological and ethical questions.

Importantly in fact, although they might be too different to be used in clinical research, animals are very similar to humans in suffering fear, pain, and agony. ${ }^{8}$ Is their pain worth this "science"?

\section{References}

1. Santer D, Kramer A, Kiss A, Aumayr K, Hackl M, Heber S, et al. St Thomas' Hospital polarizing blood cardioplegia improves hemodynamic recovery in a porcine model of cardiopulmonary bypass. J Thorac Cardiovasc Surg. 2019;158:1543-54.e8. 2. Gold H. The proper study of mankind is man. Am J Med. 1952;1:619-20. 
3. Kilkenny C, Parsons N, Kadyszewski E, Festing MFW, Cuthill IC, Fry D, et al. Survey of the quality of experimental design, statistical analysis and reporting of research using animals. PLoS One. 2009;4:e7824.

4. Hackam DG, Redelmeier DA. Translation of research evidence from animals to humans. JAMA. 2006;11:1731-2.

5. Roberts I, Kwan I, Evans P. Haig S. Does animal experimentation inform human healthcare? Observations from a systematic review of international animal experiments on fluid resuscitation. BMJ. 2002;324:474-6.
6. Pound P, Ebrahim S, Sandercock P, Bracken MB, Roberts I, Reviewing Animal Trials Systematically (RATS) Group. Where is the evidence that animal research benefits humans? BMJ. 2004;328:514-7.

7. Akhtar A. The flaws and human harms of animal experimentation. Camb $Q$ Healthc Ethics. 2015;24:407-19.

8. DeGrazia D. Taking animals seriously: mental life and moral status. Nat Mater. 1996;16:1038-46. 